\title{
Peranan Simbol Benda-Benda Langit Dalam Perkembangan Religi Masyarakat Di Indonesia
}

\section{Hartatik}

Keywords: symbol, constellation, art, culture, religi, beliefs, prehistory, history

\section{How to Cite:}

Hartatik, nfn. (1999). Peranan Simbol Benda-Benda Langit Dalam Perkembangan Religi Masyarakat Di Indonesia. Berkala Arkeologi, 19(1), 66-77. https://doi.org/10.30883/jba.v19i1.793

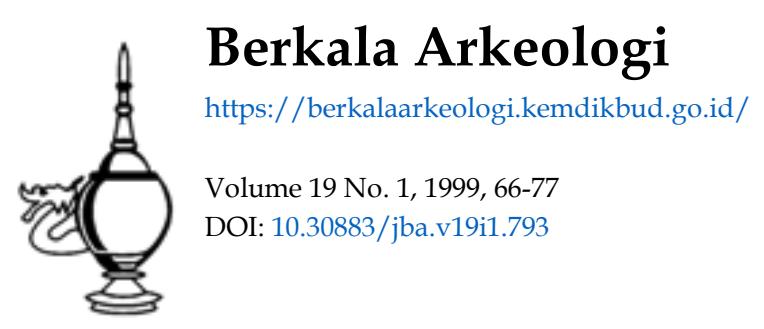

\section{c) (7)(2)}

This work is licensed under a Creative Commons Attribution-NonCommercial-ShareAlike 4.0 International License. 


\title{
PERANAN SIMBOL BENDA-BENDA LANGIT DALAM PERKEMBANGAN RELIGI MASYARAKAT DI INDONESIA
}

\author{
Hartatik \\ (Balai Arkeologi Banjarmasin)
}

\section{Pendahuluan}

Religi' dengan segala perkembangan dan penyimpangannya merupakan salah satu sisi kehidupan spiritual yang menarik. Religi merupakan fenomena sosial, kultural, dan spiritual yang mengalami evolusi dari bentuknya yang sederhana (natural religion) ke bentuk yang lebih sempurna (Pritchard, 1984: 2-7). Pendapat ini diperkuat oleh Teilhard de Cardin bahwa semakin manusia itu lebih memanusia maka ia akan semakin perlu untuk menyembah dan memperdalam religinya. Semakin manusia menyadari posisinya di alam semesta, maka ia semakin dalam dan giat untuk menyembah Sang Pencipta (Cardin, $1983: 45$ ).

Max Muller, seorang pengamat agama masa akhir abad ke-19, menganggap bahwa hal yang tidak bisa diramalkan di alam, kosmos yang tidak terbatas (the infinite) adalah sumber religi. Benda-benda alam yang besar seperti matahari, bulan, bintang, fajar, pergantian musim, dan sungai besar memberikan perasaan adanya sesuatu yang tak terbatas dan kemudian terciptalah simbol-simbol (Pritchard, 1984:28; O'dea, 1992).

Dalam kamus Populer Filsafat disebutkan bahwa simbol adalah setiap tanda yang wujudnya dapat diserap secara inderawi dan ada kaitannya dengan pengalaman dan penafsiran pribadi mengenai hakikat alam raya, manusia dan sejarahnya. Disebabkan oleh terbatasnya daya tangkap manusia, sehingga diperlukan gambar-gambar untuk merangkum dan menyimpan pengalaman, penafsiran dan harapan-harapan tersebut. Setiap benda dapat dijadikan simbol, sejauh kenyataan semesta hadir di dalam benda itu, kemudian ditangkap berdasar pengalaman pribadi dan dilihat hubungannya denga semesta alam serta maknanya (Hartoko, t.t.). Oleh karena itu hampir di semua tempat dan masa, dewa-dewa yang dipuja pada dasarnya merupakan fenomena alam yang dimanusiakan. Di sinilah peran simbol diperlukan untuk memberikan makna pada apa yang ditampilkan oleh alam semesta. Fungsi simbol pada prinsipnya adalah

\footnotetext{
' Menurut William James dan Emile Durkeim, religi adalah suatu perasaan, perbuatan, dan pengalaman yang bersifat suci. Hal yang suci tersebut dilambangkan dalam bentuk simbol dan menjadi sesuatu yang dihormati. Dalam tulisan ini pengertian religi meliputi religi dalam tingkat perkembangan yang sederhana (ketika orang belum mengenal agama) sampai masa sekarang. Dengan demikian pengertian religi lebih luas dari pada pengertian agama yang lazim digunakan di Indonesia.
} 
mengemukakan sesuatu (representamen) yang mengacu pada suatu acuan (Soedjiman \& Zoest, 1996).

Keberadaan simbol terutama yang bersifat infinite sering dikaitkan dengan religi. Dalam teori evousi religinya, R.N. Bellah menganggap bahwa perkembangan religi terdiri dari lima tahap, yaitu religi primitif, religi arkaik, religi historis, religi pra modern, dan religi modern. Pada prinsipnya, masyarakat primitif memiliki religi yang sama dengan manusia pada masa berikutnya. Pada masa primitif manusia sudah merasakan adanya kekuatan di luar dirinya, yang terekspresikan sebagai religi primitif. Adapun religi historis menemukan self, berikutnya adalah religi pra modern menemukan landasan doktrin agar dapat enerima self dengan segala kekurangan empirisnya, sedangkan religi modern mulai memahami aturan-aturan eksistensi self itu sendiri sehingga mendorong timbulnya tanggung jawab terhadap nasibnya sendiri (Bellah, 1964:303-304). Pada sisi lain, religi sebagai bentuk-bentuk simbol merupakan penghubung antara manusia dengan kondisi-kondisi yang mutlak bagi eksistensinya. Hal tersebut tampak pada gambar-gambar masa prasejarah yang diyakini memilliki kekuatan sakti dan dijadikan sebagai komunikasi dengan kekuatan di luar dirinya (Sumijati, 1984: 6).

Di Indonesia, manusia pada masa prasejarah sudah mengenal adanya religi, meskipun dalam taraf yang masih sangat sederhana. Pada masa klasik, religi tampak lebih nyata, dan sampai sekarang terasa kian sempurna dengan adanya agama-agama yang didasarkan pada kitab suci. Pada masa sekarang pun religi tidak lepas dari keberadaan simbol-simbol, terutama benda-benda langit, seperti matahari, bulan, dan bintang.

Belakangan ini ada fenomena penggunaan simbol benda-benda langit pada berbagai aspek kehidupan, bukan hanya pada religi tetapi juga pada estetika, dan etika yang meliputi aspek sosial dan politik. Untuk itu maka konsentrasi dalam tulisan ini adalah untuk mengetahui seberapa jauh peranan benda-benda langit dalam kehidupan religi masyarakat di Indonesia, perkembangan serta pergeserannya. Dengan beranalogi pada religi yang mengalami evolusi seperti yang diterangkan oleh Cardin dan Bellah, maka dalam tulisan ini juga akan diuraikan apakah peran simbol benda-benda langit juga mengalami evolusi dari yang sederhana ke lingkup yang lebih kompleks?

Untuk mengetahui hal tersebut maka dalam tulisan ini digunakan data berupa lukisan cadas, nekara, benda megalitik, artefak dari masa klasik, dan data etnografi. Data ini kemudian dianalisis dan diinterpretasikan dengan pendekatan sosiologi dan antropologi. 


\section{Lukisan Cadas, Benda Megalitik, Nekara dan Artefak Masa Klasik}

\section{II.a. Lukisan Cadas}

Pada masa prasejarah, yaitu masa berburu dan mengumpulkan makanan tingkat lanjut (sekitar 4000 tahun yang lalu), keberadaan religi sudah mulai terlihat pada lukisan cadas. Lukisan tersebut digambarkan pada dinding gua atau ceruk yang sulit dijangkau oleh manusia. Letaknya yang sulit dijangkau oleh manusia tersebut merupakan salah satu indikasi bahwa pada masa prasejarah, lukisan yang dibuat tidak dimaksudkan sebagai pemenuhan estetika semata, tetapi lebih ditekankan pada makna religinya. Oleh sebab itu, lukisan prasejarah biasanya tidak mempunyai ukuran dan bentuk yang proporsional (Sumijati, 1984:1). Lukisan cadas juga menggambarkan adanya kekuatan magis, pengalaman, dan harapan (Kempers, 1954:27).

Galis dan Roder yang meneliti lukisan cadas di Indonesia Timur, menyatakan bahwa lukisan cadas baik yang berupa cap tangan, babi rusa, perahu, matahari dan bulan berkaitan dengan upacara penghormatan nenek moyang, kesuburan, inisiasi, atau peringatan suatu kejadian penting (Soejono, 1984:159). Beberapa lukisan cadas yang menggambarkan keberadaan benda-benda langit terdapat di Ketapang (Kalimantan Barat), Lompoa (Sulawesi Selatan), Pulau Muna, Wai Tala (Seram), Kei Kecil, Danau Sentani (Gumaimit dan Pinfelu), serta di Lenehara dan Tutuala (Timor Timur). Motif matahari yang digambarkan pada lukisan cadas di Ketapang dan Metanduno berupa bentuk lingkaran dengan garis-garis sinar lurus. Di Danau Sentani, Seram, dan Kei Kecil berupa bentuk lingkaran dengan garis-garis sinar lengkung. Di Pinfelu dan Wai Tala benda-benda langit digambarkan berupa lingkaran dengan titik di tengah, di Guwaimit berupa lingkaran dengan garis-garis lengkung dan garis-garis lurus di dalam lingkaran (Kosasih, 1986:379-396).

\section{II.b Tradisi Megalitik}

Megalitik merupakan sebuah tradisi yang muncul sejak manusia mengenal bercocok tanam. Masyarakat waktu itu mempunyai konsep kepercayaan tentang kehidupan sesudah mati serta konsep adanya kekuatan alam yang tak terbatas. Mereka membuat media berupa batu atau bangunan batu sebagai medium penghormatan, tempat singgah atau lambang si mati dan untuk keselamatan arwah dari bahaya di alam roh (Soejono, 1984:204; Heekeren, 1958:45).

Sebagai sebuah tradisi, megalitik meliputi masa yang tak terbatas sampai masa perunggu besi, bahkan candi-candi masa klasik diperkirakan merupakan refleksi kelanjutan dari tradisi megalitik. Situs-situs yang mengandung temuan megalitik antara lain di Sumatra Barat (berupa menhir dan lumpang batu), Pasemah (berupa arca megalitik, menhir, peti kubur batu), Lampung (kubur batu), Gunung kidul (peti kubur 
batu), Terjan (tahta batu), dan Sulawesi Tengah (kalamba atau kubur tong batu) (Sukendar, 1987:63). Sampai sekarang, tradisi megalitik dapat ditemui pada sukusuku tertentu seperti di Sumba, Flores, Toraja, dan Nias (Sukendar, 1987:38; Soejono, 1984:205). Pada penelitian etnografinya di Nias, Haris Sukendar menemukan menhir di Orahili Goma yang mempunyai motif hias matahari yang merupakan lanbang kepala suku tertinggi (Sukendar, 1987:49).

Peninggalan megalitik tersebut kebanyakan ditemukan di puncak-puncak bukit dengan orientasi timur - barat atau menghadap ke gunung. Orientasi ke timur- barat merupakan suatu konsep yang disejajarkan dengan matahari sebagai lambang kehidupan dan kematian. Matahari dianggap sebagai salah satu kekuatan alam yang memberi kehidupan kepada manusia sejak terbit di sebelah Timur sampai tenggelamnya di sebelah barat (Soejono, 1984:222).

\section{II.c Nekara Perunggu}

Di Indonesia, nekara banyak ditemukan di wilayah Indonesia bagian Timur seperti Sumbawa, Pulau Roti, Leti, Selayar dan Pulau Kur. Di Jawa, nekara antara lain ditemukan di Temanggung, Weleri, dan Semarang. Di Bali serta beberapa wilayah lainnya juga ditemukan nekara dan moko (nekara berukuran kecil dan bentuknya agak tanbun).

Pola hias yang terdapat pada nekara mempunyai kecenderungan pelukisan yang bersifat simbolis maupun estetis seperti gambar manusia yang distilir dalam bentuk bulu - bulu burung. Selain itu, hampir pada semua nekara, pada bidang pukulnya terdapat motif hias berupa pola bintang bersinar yang dikelilingi oleh motif hias geometris dan stiliran bulu burung. Motif hias bintang bersinar tersebut erat kaitannya dengan benda-benda langit seperti guntur dengan suaranya yang menggelegar. Dengan demikian motif hias tersebut tentunya mengandung harapan yang berkaitan dengan fungsi nekara (sebagai genderang dalam upacara memanggil hujan dan upacara resmi kenegaraan atau adat) agar bunyi nekara dapat menggelegar dan menyebar ke berbagai penjuru seperti halnya bunyi guntur (Kempers, 1984:115).

\section{II.d. Artefak Masa Klasik}

Pada masa klasik, di Jawa tumbuh kerajaan-kerajaan besar yang membangun candicandi sebagai tempat peribadatan. Candi-candi tersebut ternyata masih terpengaruh oleh tradisi megalitik, terutama tampak pada bentuk dan susunannya. Menurut Geldern, hal tersebut terjadi karena tradisi megalitik telah bercampur dengan seni 
arsitektur Jawa-Hindu dan konsep siwaisme yang terefleksi dalam penggunaan punden berundak sebagai obyek pemujaan.

Salah satu kerajaan masa klasik terbesar di Jawa adalah kerajaan Majapahit. Kerajaan yang wilayahnya meliputi hampir seluruh Nusantara ini penduduknya menganut agama Hindu Budha. Dari masa Majapahit dikenal adanya Surya Majapahit, yaitu sebuah simbol kejayaan kerajaan Majapahit, berbentuk lingkaran yang dikelilingi oleh garis-garis sinar berjumlah empat atau kelipannya. Simbol tersebut dipahatkan pada sebuah batu yang ditemukan di candi Candi Bangkal, Candi Penataran, Candi Rimbi, Candi Jabung, pada arca Reco Pengantin di Jebuk (Tulung Agung), dan pada makam Islam di Tralaya. Di Bali, batu Surya Majapahit selalu diletakkan di sudut kanan di halaman dalam candi dengan orientasi menghadap Gunung Agung. Batu Surya Majapahit tersebut dianggap sebagai kepala dewa-dewa (Miksic, 1995:124; Munandar, 1997).

Dalam masyarakat Bali Hindu, pemujaan kepada Dewa Surya (Matahari) masih tampak dalam upacara-upacara tertentu untuk memohon perlindungan dan keselamatan bagi masyarakat (Sutaba, 1996:7). Adapun kendaraan Dewa Surya yaitu kereta, mempunyai roda berupa cakra atau roda matahari atau sering juga disebut sebagai cakra visnu. Roda matahari tersebut mempunyai empat atau delapan ruji-ruji yang merupakan lambang matahari (Hoop, 1949:294).

\section{II.e. Data Etnografi}

Ada beberapa suku murba ${ }^{2}$ di Indonesia yang masih melaksanakan upacara ritual berkaitan dengan benda-benda langit, yaitu suku-suku di Flores Tengah, Sumba, Alor, Timor, dan Seram (Hadiwiyono, 1985:21-43). Beberapa suku di Flores percaya bahwa langit dan bumi, matahari dan bulan adalah sebagai dewa yang tertinggi. Dalam upacara sesaji tokoh dewa tersebut disebut Langit atas-Bumi bawah atau MatahariBulan. Suku Manggarai di Flores percaya adanya Mori Keraeng (Tuhan Segala Raja) yang menciptakan segala sesuatu, pelindung, dan pemelihara manusia. Selain itu Mereka juga percaya adaya roh atau tokoh yang menguasai rohani dunia.

Di Sumba, ada suku yang percaya adanya Marapu, yaitu alam ghaib yang meliputi dewa, roh, jiwa, serta benda-benda duniawi yang menjadi simbol Marapu. Marapu Langit dan awan berada di alam atas dan menguasai hidup dan nasib manusia. Sedangkan Marapu Kabala (batu meteor) disimpan dalam sebuah wadah dapat digunakan sebagai perantara untuk mencelakakan musuh. Mereka percaya bahwa

${ }^{2}$ Meminjam istilah Hadiwiyono, suku murba adalah suku yang masih hidup pada masa sekarang tetapi masih malakukan kegiatan yang merupakan tradisi prasejarah. 
orang yang gugur di medan perang arwahnya akan langsung menuju ke langit dan menjadi bintang.

Di daerah Alor dan Timor ada kelompok suku yang memuja Upolero (kakak matahari) dan Upunusa (ibu bumi) sebagai tokoh dewa yang tertinggi dan merupakan penjelmaan azas laki-laki dan perempuan. Di atas Upolero ada tokoh yang lebih tinggi yaitu It Matroomi (Tuhan Kita). Sementara itu di beberapa daerah, Dewa Matahari dianggap sebagai azas laki-laki, sedangkan bumi sebagai azas perempuan.

Di daerah Aru, Kei, dan Tanimbar pasangan tokoh kosmis bukan matahari - bumi tetapi matahari-bulan. Tokoh dewa tertinggi yang sering disebut dalam mantra-mantra adalah Duad Ler Wulan (Tuhan matahari - Bulan). Itu berarti bahwa matahari dan bulan merupakan dua aspek dewa tertinggi. Selain dewa-dewa tersebut, masyarakat di Indonesia Timur ini lebih mengutamakan pemujaan kepada arwah nenek moyang (Hadiwiyono, 1985:33-34).

Suku-suku di Seram pada umumnya percaya dan menyembah langit dan bumi atau matahari dan bulan sebagai dewa tertinggi. Di Seram barat, matahari disebut sebagai Lia matai dan bulan disebut sebagai Bulane. Pada masyarakat Seram Barat terdapat mitos bahwa manusia pertama lahir dari perkawinan antara matahari dan bulan. Di Seram Tengah, tokoh yang dipandang sebagai dewa tertinggi adalah Allah Ta'ala yang merupakan pengaruh dari agama Islam.

Selanjutnya istilah Allah Alatala digunakan untuk menyebut tokoh dewa tertinggi di Toraja Barat. Alatala mempunyai nama-nama tambahan seperti Topeteru (Sang Pembentuk), Topebagi (Sang Pembangi nasib), Topejadi (Sang Pencipta) dan sebagainya. Proses penjadian bermula dari perkawinan langit dan bumi yang kemudian melahirkan matahari dan bulan. Matahari dan bulan menikah dan lahirlah bintang-bintang. Sedangkan Alatala sebagai Topeteru membuat sepasang manusia dari tanah liat (Hadiwiyono, 1985:49).

Simbol matahari juga terdapat dalam upacara adat Toraja, antara lain pada upacara Puang Tuhal. Upacara yang erat kaitannya dengan matahari sebagai sumber kehidupan ini diadakan pada saat matahari terbit. Simbol matahari juga digambarkan pada motif hias adat Tongkonan, seni ukir Toraja dan peti mati (Hakim, 1997:226). Pada beberapa kepercayaan kosmologi Bugis Makasar, masih terdapat aktivitas yang memuja matahari dan bulan sebagai aspek perwujudan arah Timur dan Barat (Wibisono, 1990:165-174). 


\section{Pembahasan}

Pada lukisan cadas masa prasejarah, keberadaan benda-benda langit terutama matahari dan bulan merupakan lambang terang dan kesuburan. Tidak begitu jelas apakah hal tersebut berarti pula pendukung lukisan cadas tersebut sudah mempunyai konsep kepercayaan pemujaan terhadap dewa matahari dan bulan atau belum, tetapi data etnografi pada suku - suku murba menunjukkan bahwa matahari dan bulan sering disebut dan diperlakukan sebagai dewa yang mempunyai kedudukkan tinggi. Para pendukung tradisi megalitik menganggap matahari sebagai tokoh yang diagungkan. Hal tersebut tampak pada orientasi bangunan megalitik yang sebagian besar menghadap ke arah Barat - Timur, selain ada juga yang mengarah ke gunung. Dengan demikian dapat dikatakan bahwa pendukung tradisi megalitik juga berkonsepsi tentang langit, bintang, matahari dan bulan sebagai tempat asal dan tempat berpulangnya arwah.

Keberadaan benda-benda langit pada pola hias nekara yang diwujudkan dalam pola bintang bersinar lebih cenderung kepada fungsi estetis dan simbol harapan. Dengan adanya pola bintang bersinar tersebut diharapkan jika nekara tersebut dipukul maka bunyi nekara akan menggelegar dan menyebar ke berbagai arah.

Pada masa pengaruh Hindu Budha (masa klasik), keberadaan simbol benda langit yaitu matahari dapat diketahui dari kepercayaan pemeluk Hindu yang memuja dewa Surya atau Dewa Matahari. Pada masa Kerajaan Majapahit, keberadaan Surya Majapahit, sebagai simbol kejayaan kerajaan masih dapat dijumpai pada makam Islam di Tralaya (Jawa Timur). Ini menunjukkan bahwa bahwa pada masa Islam pun pengaruh serta penggunaan simbol benda-benda langit masih cukup kuat.

Kuatnya pengaruh dan penggunaan simbol benda-benda langit dalam kehidupan religi juga masih tampak pada kehidupan suku-suku murba seperti di Flores, Sumba, Alor, Timor dan Seram, meskipun pengaruh Islam atau Kristen telah masuk di wilayah tersebut. Kekentalan tersebut tampak pada kalimat mantra-mantra atau do'a, pada cerita-cerita mitos maupun pada pola hias yang hampir semuanya menggambarkan benda-benda langit terutama matahari dan bulan sebagai asal segala sesuatu atau sebagai zat tertinggi. Anggapan atau kepercayaan benda-benda langit sebagai zat tertinggi tersebut sulit hilang karena menjadi suatu kepercayaan yang sudah turun temurun dan sebagai sesuatu yang infinite, anggapan itu sudah sangat mendarah daging.

Dalam perkembangannya, fenomena benda-benda langit yang bersifat prasarana religi dapat dilihat pada agama Islam. Sejak abad pertengahan, ilmu perbintangan (ilmu falak ) telah dikembangkan oleh ilmuwan-ilmuwan muslim untuk kepentingan praktis religis yang erat kaitannya dengan penentuan waktu sholat, puasa, dan haji. Dalam 
Islam, shalat merupakan kewajiban yang harus dilakukan lima kali dalam sehari semalam yaitu shalat Isya, Shubuh, Dhuhur, Ashar dan Maghrib yang masing-masing waktunya ditetapkan menurut peredaran matahari. Selain itu ada ibadah puasa yang dilakukan pada bulan Ramadhan, sedangkan ibadah Haji dikerjakan pada bulan Dzulhijah. Ramadhan dan Dzulhijah adalah nama-nama bulan dalam tahun Hijriyah yang perhitungannya berdasarkan pada peredaran bulan. Dalam perhitungannya, satu tahun Hijriyah dengan satu tahun Masehi (yang berdasar peredaran matahari ) terdapat selisih sekitar 11 hari. Satu tahun Masehi ada 365 hari, satu tahun Hijriyah ada 354 hari (Ibrahim, 1995).

Perlakuan masyarakat sekarang terhadap benda-benda langit tampak lebih kompleks, tidak hanya seputar religi tetapi meluas ke etika yang meliputi tingkah laku sosial dan politik. Fenomena pemujaan benda langit secara langsung hampir tidak dapat ditemui lagi, tetapi bergeser menjadi suatu kepercayaan peruntungan nasib, antara lain berupa Astrologi, horoskop, atau ramalan zodiak. Ramalan Astrologi tersebut sebenarnya menggunakan unsur-unsur astronomi yaitu gerakan planet - planet yang dihubungkan dengan manusia tetapi kemudian dibumbui dengan mitos-mitos Yunani dan Romawi Kuno. Astrologi menganggap langit sebagai lingkaran besar yang dibagi menjadi dua belas bagian yang disebut sebagai zodiak (yaitu dari Capricornus sampai Sagitarius) Masing-masing zodiak mempunyai sifat yang merupakan analogi dari dewa-dewa Yunani dan Romawi Kuno. Ada golongan tertentu yang sangat tertarik dan mempercayai astrologi untuk mencari jawaban dan keberuntungan, sehingga bagi mereka astrologi hampir menjadi agama pengetahuan (Strohmer, 1988:15-20).

Begitu berartinya peran benda-benda langit (terutama matahari, bulan, bintang) dalam prasarana religi, sehingga pada masa modern pun simbol benda-benda langit tersebut sering digunakan sebagai simbol atau lambang organisasi sosial atau politik yang bernafaskan religius (yang didominasi oleh kelompok religi tertentu). Dalam perjalanan orsospol di Indonesia pasca kemerdekaan, terdapat beberapa partai politik yang berlambangkan benda-benda langit, seperti Masyumi yang berlambang bulan sabit, Partai Persatuan Pembangunan (PPP) yang berlambang bintang (sebelum kembali ke lambang ka'bah) Partai Amanat Nasioanal (PAN) dengan lambang matahari terbit serta Partai Bulan Bintang (PBB), sebuah parpol baru pada pertengahan tahun 1998 yang berlambang bulan dan bintang. Selain itu, simbol bulan bintang juga dipakai sebagi simbol beberapa organisasi sosial kemasyarakatan seperti Muhammadiyah serta Mathla'ul Anwar yang merupakan organisasi sosial masyarakat Banten Simbol atau lambang berupa benda-benda langit tersebut dipakai dengan harapan agar organisasi mereka bisa bersinar seperti halnya benda-benda langit (terutama matahari dan bulan) yang memberi energi kehidupan dan bermaanfaat bagi masyarakat. 
Keberadaan benda-benda langit scperti matahari, bulan, dan bintang secara praktis dapat dirasakan manfaatnya oleh seluruh masyarakat. Ilmu perbintangan atau

astronomi sangat diperlukan antara lain untuk mengetahui cuaca dan petunjuk arah bagi penerbangan dan pelayaran (navigasi). Dalam arti harafiahnya, benda-benda langit tetap berperan karena manusia selalu menggunakan matahari dan bulan scbagai patokan penghitungan waktu dan memanfaatkan energi matahari untuk berbagai keperluan hidup

\section{Kesimpulan}

Benda-benda langit selalu hadir dalam bentuk simbol-simbol yang tergambar pada lukisan cadas, nekara, konsep megalitik, simbol kejayaan kerajaan maupun dalam mitos konvensional seperti yang dapat ditemui pada data etnografi beberapa suku di Indonesia. Secara umum, benda-benda langit, terutama matahari, bulan dan bintang merupakan simbol yang sinamya dianggap sebagai sumber kehidupan, cahaya kebenaran dan keadilan yang diharapkan mampu menyinari umat manusia.

Dalam perkembangannya, peran benda-benda langit mengalami pergeseran dari fungsi religius ke fungsi global yang cenderung profan yang meliputi fungsi sosial dan politik. Meskipun demikian, kahadiran simbol yang mewakili tokoh yang infinite (tak terbatas) tersebut selalu ada sebagai pembangkit perasaan kebersamaan dan keterikatan yang lebih dalam dari sekedar formulasi verbal.

\section{KEPUSTAKAAN}

Atmosudiro, S. (1984). Lukisan Manusia Di Pulau Lomblen, Flores Timur (Tambahan Data Hasil Seni Bercorak Prasejarah). Berkala Arkeologi, 5(1), 1-8. https://doi.org/10.30883/jba.v5i1.262

Bellah, R.N. 1995. "Evolusi Agama", Agama: Dalam Analisa dan Interpretasi Sosiologis. Robertson, Roland. ed. Saifuddin, Akhmad Fedyani, terjemah. Jakarta : P.T. Raja Grafindo Persada.

Cardin, Teilhard de \& Kopp, Joseph V. 1983. Teori Evolusi-Sintesa Baru Teilhard de Cardin. Yogyakarta: Yayasan Kanisius.

Child, Alice B \& Irvin L. 1992. Religion and Magic in The Life of Traditional People. New Jersey: Prentice Hall. 
Crapps, Robert W. 1993. Gaya Hidup Beragama, Autoritas Yang Sedang Menjadi Mistik, terjemah oleh A. H. Hardjana. Yogyakarta: Penerbit Kanisius.

Driwantoro, Dubel, 1989. "Religi dan Pertanian", AHPA III. Jakarta: Puslit Arkenas, hlm. 373-382.

Hadiwijono, Harun, 1985. Religi Suku Murba di Indonesia. Jakarta: BPK. Gunung Mulia.

Hakim, Budianto, 1997. "Simbol Dalam Masyarakat Toraja: Suatu Aspek Tradisi Megalitik", PIA VII. Jakarta: Puslit Arkenas, hlm. 220-229

Hartoko, Dik. t.t Kamus Populer Filsafat. Jakarta : CV. Rajawali.

Hoop, ANJ.TH.ATH van der 1949. Indonesische Siermotieven, Indonesian Ornamental Design, Ragam-Ragam Perhiasan Indonesia. Jakarta: Koninkllijk Bataviaasch Genootschap van Kunsten Wetenscchappen.

Ibrahim, Salamun K.H. 1995. Ilmu Falak: Cara Mengetahui Awal Tahun, Awal Bulan, Arah Kiblat, Musim dan Perbedaan Waktu. Surabaya: Pustaka Progresif.

Kempers, A.J. Bernet. 1959. Ancient Indonesian Art. Cambridge: Harvard University Press.

1988. The Kettledrums of Southeast Asia, a Bronze Age World and its Aftermath, Rotterdam: A.A. Balkema.

Kosasih, S.A. 1986. "Studi Komparatif Tentang Lukisan-Lukisan Gua Prasejarah di Kawasan Asia Tenggara", PIA IV. IIb. Jakarta : Puslit Arkenas, hlm. 379396.

1987. "Lukisan Gua Prasejarah, Bentangan Tema dan Wilayahnya", DIA II, Estetika Dalam Arkeologi Indonesia. Jakarta : Puslit Arkenas, hlm. 16-37.

Kusen, d.k.k. 1993. "Agama dan Kepercayaan Masyarakat Majapahit" 700 Tahun Majapahit (1293-1993). Suatu Bunga Rampai. Sartono Kartodirjo, d.k.k. (ed). Surabaya: Dinas Pariwisata Daerah Tingkat I Jawa Timur.

Lowie, Robert. H. 1970. Primitive Religion. New York : Liveright Publishing Corporation. 
Miksic, John N. ed. 1995. The Legacy of Majapahit. Singapore: Natioanal Heritage Board.

Najib, TB. 1987. Dinamika Perjuangan Pemuda Mathla'ul Anwar dan Perjuangannya. Tidak diterbitkan.

Nottingham, Elizabeth K. 1996. Agama dan Masyarakat, Suatu Pengantar Sosiologi Agama. Jakarta: PT. Raja Grafindo Persada.

O'dea, Thoomas F. 1992. Sosiologi Agama. terjemah oleh Yasogama. Jakarta Rajawali Press.

Pritchard, E.E. Evans. 1984. Teori-Teori Tentang Agama Primitif. Ludjito, terjemah. Yogyakarta: PLP2M..

Soejono, R.P. 1984. Sejarah Nasional Indonesia I. Jakarta : Departemen Pendidikan dan Kebudayaan.

Strohmer, Charles. 1988. Rahasia di Balik Astrologi. Bandung: Yayasan Kalam Hidup.

Subagya, Rahmat. 1976. Kepercayaan, Kebatinan, Kerohanian, Kejiwaan, dan Agama. Yogyakarta : Yayasan Kanisius.

Sudjiman, Panuti \& Zoest, Aart van. 1996. Serba-Serbi Semiotika. Jakarta : PT. Gramedia Pustaka.

Wibisono, Sony Chr. 1990. "Masalah Keletakan Kuburan dalam Sistem Permukiman, Suatu Studi Kasus di Pulau Selayar". AHPA I. Jakarta : Puslit Arkenas., hlm. 165-174. 

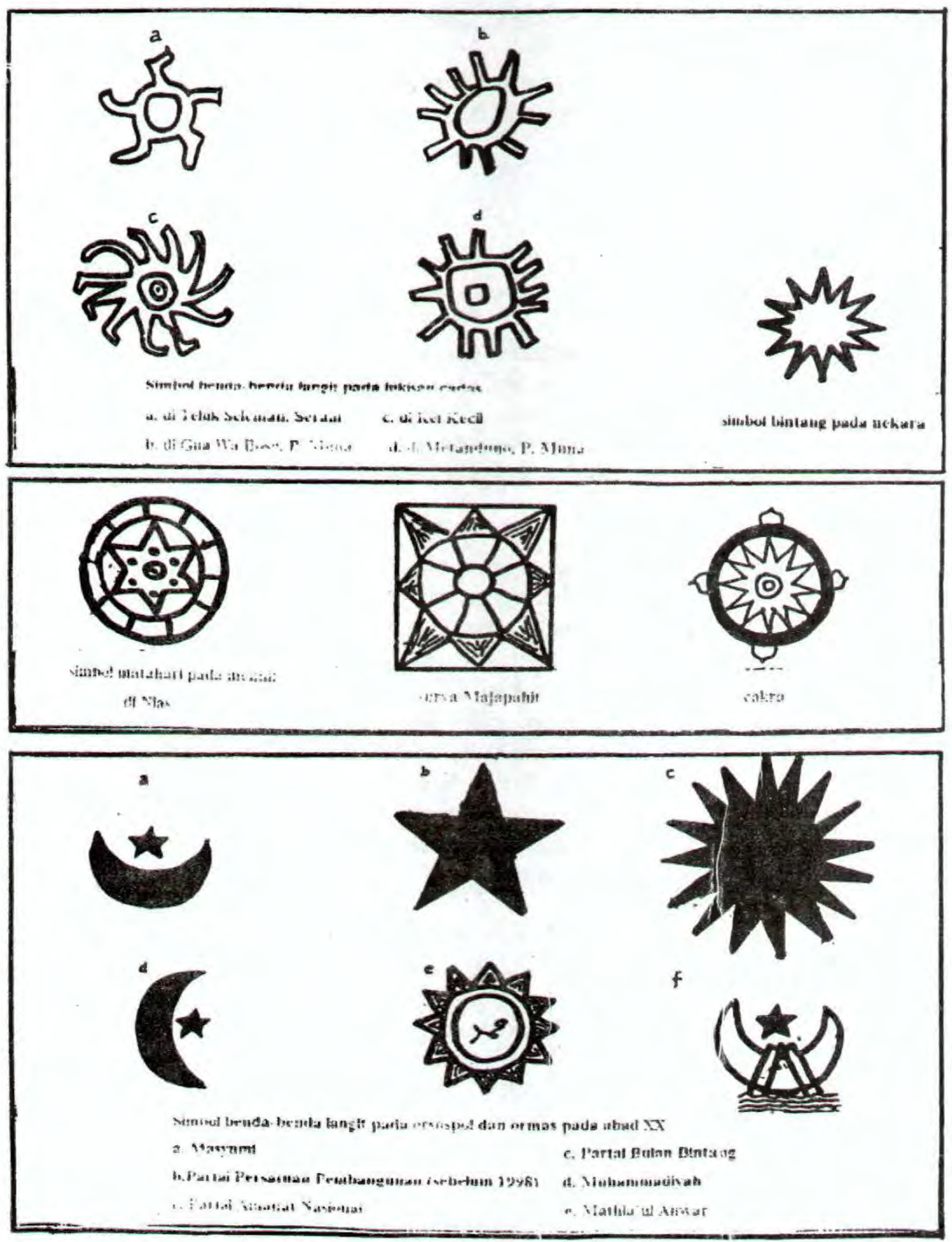

Berkala Arkeologi Th. XIX (1) 